\title{
Effect of Laser Energy on the Tribology Properties of $\mathrm{MoS}_{2}$ Flakes
}

\author{
M. Mahdavia, S. Kimiagarb,*, F. Abrinaeic \\ a Department of Physics, Central Tehran Branch, Islamic Azad University, Tehran, Iran, \\ ${ }^{b}$ Nano Research Lab (NRL), Department of Physics, Central Tehran Branch, Islamic Azad University, Tehran, Iran, \\ c Department of Physics, East Tehran Branch, Islamic Azad University, Tehran, Iran.
}

Keywords:

$\mathrm{MoS}_{2}$

Hydraulic

Lubricant

Laser

Few-layered

Oil

* Corresponding author:

Salimeh Kimiagar

E-mail: s_kimiagar@iauctb.ac.ir

Received: 4 November 2019

Revised: 15 January 2020

Accepted: 28 February 2020

\begin{abstract}
A B S T R A C T
The present study reports the novel synthesis of few-layered $\mathrm{MoS}_{2}$ flakes for hydraulic applications. The few-layered MoS flakes were prepared by using hydrothermal method and laser irradiation assistant at different energy levels from 40 to $80 \mathrm{~mJ}$. XRD patterns indicated a hexagonal structure for the samples. The crystallite sizes experienced a decrease from 50 to $15 \mathrm{~nm}$ by increasing laser energies. Raman spectra revealed a slight red-shift and blue-shift by increasing laser energies. The Zeta potential values increased by enhancement of laser energy that maximum value achieved for $80 \mathrm{~mJ}$ laser energy. The viscosity index of the samples increased when increasing the laser energy, decreasing the viscosity variations with the temperature varies. The laser irradiation can improve the limits of temperature of the fluid containing a fewlayered $\mathrm{MoS}_{2}$ flakes making them suitable for industrial applications. The friction coefficient were reduced for the base oil containing few-layered $\mathrm{MoS}_{2}$ flakes additive irradiated under $80 \mathrm{~mJ}$ laser energy. The results suggest that laser irradiation can improve the hydraulic properties when including a few-layered $\mathrm{MoS}_{2}$ flakes. Few-layered $\mathrm{MoS}_{2}$ may be a promising candidate for applications as oil additives.
\end{abstract}

(C) 2020 Published by Faculty of Engineering

\section{INTRODUCTION}

The industry has recently witnessed an increase in demand for solid lubricant purposes. Solid lubricating materials can be dispersed in a solid matrix or added to lubricating oil as an additive. Efficient boundary lubrication, reduce in friction, and minimize wear in extreme operating environments are the benefits of using the solid lubricants. It is possible to improve lubricant performance by combining different types of lubricants that leads to control of friction, avoiding wear, and corrosion protection. The soft-metal solid lubricants, graphite, polytetrafluoroethylene (PTFE), molybdenum disulfide $\left(\mathrm{MoS}_{2}\right)$, and white solids are known as examples of solid lubricants. Each of these materials, in its turn, has advantages and disadvantages for using as lubricants.

Nowadays, nano-lubricants have attracted much attention due to the possibility of controlling the 
size distribution and shape. Selection of materials and a synthetic method that not only can provide better lubricant properties but also it has the ability to produce large-scale for industrial applications, has become an important challenge in this field. $\mathrm{MoS}_{2}$ as a transition metal dichalcogenide has been more known due to its inherent structural characteristics that composed of strong covalently S-Mo-S sheets that held together by weak van der Waals interlayer interactions [1]. The reduction layer is possible by micromechanical exfoliation from bulk crystalline due to weak interlayer interactions [2]. $\mathrm{MoS}_{2}$ has drawn wide attention due to the applicability as catalytic materials for hydrodesulphurization and gas storage, catalyst for coal liquefaction, solar cells, and new generation of semiconductors and high-rate lithium battery [3-8]. Among solid lubricants, the lamellar materials such as graphene and $\mathrm{MoS}_{2}$ are especially important due to the formation of individual atomically-thin planes that lead to the easily slip over each other [9, 10]. This is while paying more attention to $\mathrm{MoS}_{2}$, realizing its use as a dry lubricant or additive to lubricating oils to reduce friction [11]. Gustavo Tontini et al. investigated the stability and tribological properties of nanostructured flowerlike $\mathrm{MoS}_{2}$ particles dispersed in two different lubricants with $1 \mathrm{Wt} . \%$ of $\mathrm{MoS}_{2}$ nanoflowers and found that a ramified polyolester-based nano-oil showed no decrease in its average friction coefficient, while a naphthenic-based nano-oil presented a remarkable 86 percent reduction [12]. Due to the excellent properties such as adhesion, wide service-temperature range, fretting corrosion protection, reduction of friction with enhance in loads, avoiding stickslip, High load carrying capacity, $\mathrm{MoS}_{2}$ is at the center of attention in the field of lubricants [1315]. According to literature, $\mathrm{MoS}_{2}$ in few-layered form had better stability and solubility in organic solvents or lubricating oils [16-18]. So far, many methods such as sulfurization of molybdenum salts, chemical vapor deposition and sonochemical, electrochemical deposition, thermal decomposition, solvothermal and hydrothermal methods have been used to synthesize the $\mathrm{MoS}_{2}$ nanostructures [19]. Among the above-mentioned methods, the hydrothermal method is a useful procedure for synthesis of $\mathrm{MoS}_{2}$ nanostructures due to the simplicity in the method, convenient in control of size and shape, cost-effectiveness, and high-performance products.
The present study describes a novel method to the large-scale synthesis of few-layered $\mathrm{MoS}_{2}$ flakes. First, nanocrystalline particles of $\mathrm{MoS}_{2}$ were synthesized by a hydrothermal method and then they thinned by reduction of layers using the laser beam irradiation. Finally, the obtained few-layered $\mathrm{MoS}_{2}$ used as an additive to the hydraulic oils and its effects was studied.

\section{EXPERIMENTAL METHODS}

\subsection{SYNTHESIS OF FEW-LAYERED MOS ${ }_{2}$ FLAKES}

All materials using in these experiments were purchased from Merck Company. $\mathrm{MoS}_{2}$ nanosheets prepared by a solution of $0.1 \mathrm{M}$ ammonium heptamolybdate $\left(\left(\mathrm{NH}_{4}\right)_{6} \mathrm{Mo}_{7} \mathrm{O}_{24}\right)$ and $0.2 \mathrm{M}$ thiourea $\left(\mathrm{CH}_{4} \mathrm{~N}_{2} \mathrm{~S}\right)$ in ethanol that stirred at $60{ }^{\circ} \mathrm{C}$ for $30 \mathrm{~min}$ to achieve a milky homogeneous solution. Then, the solution filled into a $100 \mathrm{~mL}$ container placed into the Teflon lined stainless steel autoclave. The reaction carried out at $220{ }^{\circ} \mathrm{C}$ for $12 \mathrm{~h}$. After cooling down to room temperature the obtained black powder washed twice with ethanol and dried in a vacuum oven at $80{ }^{\circ} \mathrm{C}$. Few-layered $\mathrm{MoS}_{2}$ was prepared by a suspension of $0.5 \mathrm{~g}$ of $\mathrm{MoS}_{2}$ nanosheets which dispersed in $20 \mathrm{~mL}$ ethanol for $20 \mathrm{~min}$. Three of this suspension separately was exposed under $532 \mathrm{~nm} \mathrm{Nd:YAG} \mathrm{pulsed} \mathrm{laser}$ irradiation $(5 \mathrm{~ns}$ pulse duration and $7 \mathrm{~mm}$ beam diameter) with 40,60, and $80 \mathrm{~mJ}$ energy for 15 min. A flow chart of the experimental procedure is shown in Fig. 1

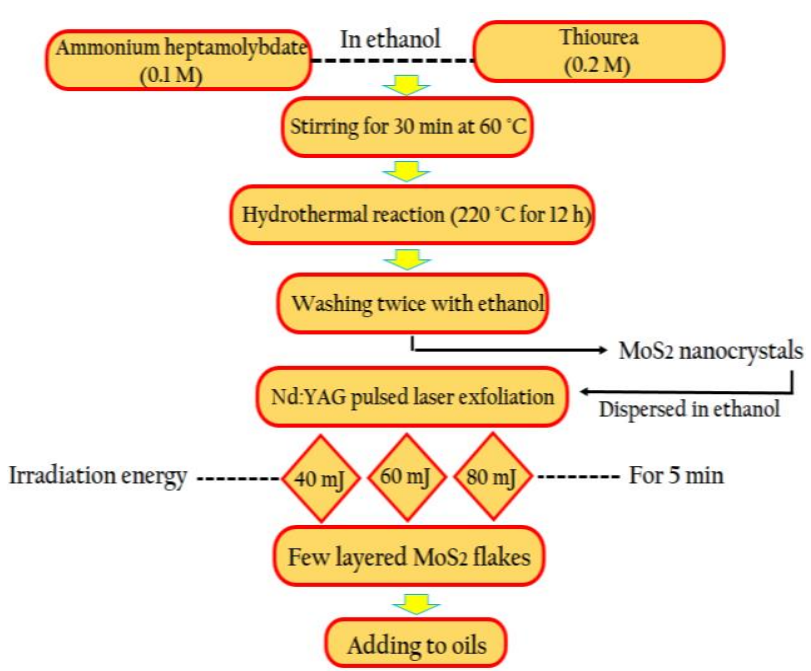

Fig. 1. Flowchart of the experimental process for the synthesis of few-layered $\mathrm{MoS}_{2}$. 


\subsection{ADDING THE FEW-LAYERED MOS $_{2}$ FLAKES TO OIL}

In order to investigate the effect of the few-layered $\mathrm{MoS}_{2}$ flakes, the nano-sheets with the concentration of $0.02 \mathrm{~g} / \mathrm{L}$ were dispersed in oil ( $\mathrm{T}$ 68, DIN-51524 part II HLP). Then it was placed into the ultrasonic bath for $12 \mathrm{~h}$ to achieve homogeneous solution. The Oil (0) and Oil (1) referred to the pure oil without any nanomaterial and the $\mathrm{MoS}_{2}$ nanosheets additive, respectively. Similarly, the Oil (40), Oil (60), and Oil (80) are attributed to few-layered $\mathrm{MoS}_{2}$ flakes after 15 minutes irradiation under 40,60, and $80 \mathrm{~mJ}$ laser energy, respectively.

\subsection{CHARACTERIZATION}

The structure of fabricated samples characterized by X-Ray diffraction (XRD) using X'Pert PRO, Philips with $\mathrm{Cu}-\mathrm{K} \alpha$ radiation $(\lambda=0.154 \mathrm{~nm})$. Transmission Electron Microscopy (TEM), Philips $\mathrm{XL}$, conducted to determine the morphology and structure of the samples. Raman spectroscopy (HR-800, JobinYvon) was utilized to specify the structure, quality and the number of $\mathrm{MoS}_{2}$ layers. The Raman spectra were recorded in a range from 300 to $3000 \mathrm{~cm}^{-1}$ with $0.5 \mathrm{~cm}^{-1}$ spectral resolution. A four-ball tribometer was used to study the friction coefficient and wear scar of the prepared samples. The four-ball test machine was used to estimate the wear preventive characteristics of the lubricant (Fig. 2). Oil Analysis Condition Monitoring was done by Alborztadbirkaran Iranian Company. Kinematic viscosity was determined at 40 and $100{ }^{\circ} \mathrm{C}$ using ASTM D2270 method to know about viscosity variations at different temperatures. Pour point, which is a liquid flowing temperature, and flash point that is a possible dilution of oil was measured. Kinematic viscosity specified as the measurement of the resistance of a fluid to flow under gravity conditions.

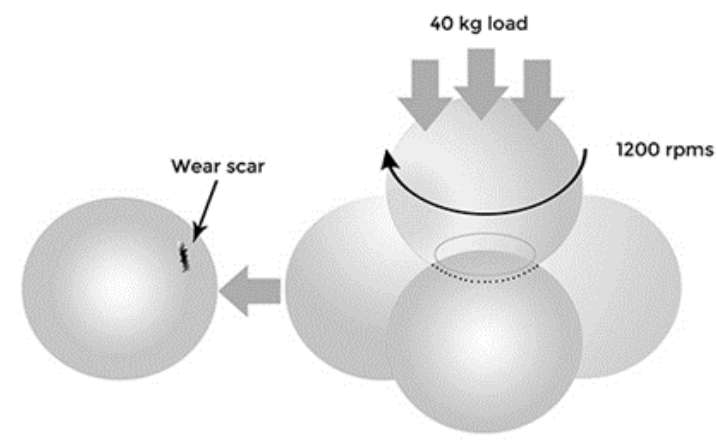

Fig. 2. Schematic of a four-ball test machine.

\section{RESULTS AND DISCUSSION}

\subsection{STRUCTURAL INVESTIGATIONS}

Figure 3 shows the crystal structure of the $\mathrm{MoS}_{2}$ nanosheets and few-layered $\mathrm{MoS}_{2}$ flakes were studied by powder X-ray diffraction (XRD) as a function of the processing conditions. All the samples exhibited the crystallite nature of $\mathrm{MoS}_{2}$ materials with some typical peaks at $14.2^{\circ}$, $32.6^{\circ}, \quad 39.5^{\circ}, 44.2^{\circ}, 49.8^{\circ}$, and $58.3^{\circ}$, corresponding to the (002), (100), (103), (006), (105), and (110) planes of hexagonal $\mathrm{MoS}_{2}$ structure with lattice constants $\mathrm{a}=\mathrm{b}=0.315 \mathrm{~nm}$, and $c=1.229 \mathrm{~nm}$ (JCPDS NO. 37-1492). The (002) peak corresponding to a d-spacing of 0.62 $\mathrm{nm}$ demonstrated the stacking of single layers, while peaks with higher angle offer information about the crystallinity of the samples [20]. Decreasing of (002) peak intensity suggested the more reduction in thickness of $\mathrm{MoS}_{2}$ flakes $[21,22]$. It is noticed that the $(002)$ diffraction peak of the few-layered $\mathrm{MoS}_{2}$ flakes after laser irradiation experiences a shift to the lower angles leads to an increase in d-spacing and it indicated the de-stacking of $\mathrm{MoS}_{2}$ layers. It can be concluded that the average grain size of the $\mathrm{MoS}_{2}$ nanosheets were gradually decreased with the increase in the energy of laser irradiation. To some extent, the widened diffraction peaks also confirmed the reduction of the initial size of the $\mathrm{MoS}_{2}$ nanosheets, which was caused by the laser irradiation. Further details obtained from XRD data and estimated crystallite size of the samples using the Williamson- Hall plot [23] are listed in Table 1.

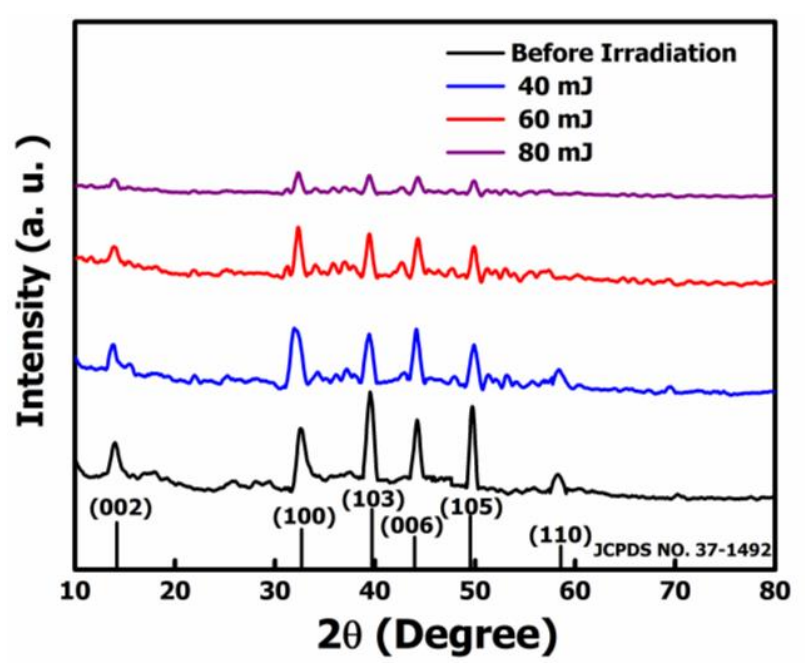

Fig. 3 XRD patterns of the $\mathrm{MoS}_{2}$ structures under various laser energies from 40 to $80 \mathrm{~mJ}$. 
The calculated strain from the XRD data is also collected in Table 1 . The results illustrated that the strain was the occurrence of the $\mathrm{MoS}_{2}$ nanosheets damage during the laser irradiation, while it was broken because of the laser damage it changed its position, proving the existence of the strain [24]. This finding indicates that the inplane strain can affect the dominant covalent bonding between Mo and S atoms. This would amend the electronic properties of monolayer $\mathrm{MoS}_{2}$ by the induced strain [25].

\subsection{MORPHOLOGICAL OBSERVATIONS}

TEM images of the $\mathrm{MoS}_{2}$ samples were performed to investigate the structural deviations that occur after various laser irradiation energies (Figs. 4c4d). In Fig. 4b the large area could be distinguished. By increasing laser irradiation energy, decreasing of the layers are apparent. Fig. $4 \mathrm{~d}$ shows few-layered $\mathrm{MoS}_{2}$ flakes with folding at the edge, which is known as a commonly occurred phenomenon in two-dimensional materials.

Table 1. Collected data from XRD analysis.

\begin{tabular}{|c|c|c|c|c|c|}
\hline Sample & $2 \theta$ (deg.) & $(\boldsymbol{h} k l)$ & $\boldsymbol{d}(\AA)$ & $\varepsilon$ & $\begin{array}{l}\text { Crystallite } \\
\text { size (nm) }\end{array}$ \\
\hline \multirow{5}{*}{$\begin{array}{l}\text { Before } \\
\text { Irradiation }\end{array}$} & 14.18 & $(002)$ & 6.246 & \multirow{5}{*}{$\begin{array}{l}0.27 \times \\
10^{-2}\end{array}$} & \multirow{5}{*}{55.6} \\
\hline & 32.56 & $(100)$ & 2.740 & & \\
\hline & 39.53 & $(103)$ & 2.270 & & \\
\hline & 44.21 & $(006)$ & 2.049 & & \\
\hline & 49.73 & $(105)$ & 1.834 & & \\
\hline \multirow{5}{*}{$40 \mathrm{~mJ}$} & 14.08 & $(002)$ & 6.280 & \multirow{5}{*}{$\begin{array}{l}1.40 \times \\
10^{-2}\end{array}$} & \multirow{5}{*}{20.7} \\
\hline & 32.31 & $(100)$ & 2.771 & & \\
\hline & 39.41 & $(103)$ & 2.287 & & \\
\hline & 44.16 & $(006)$ & 2.051 & & \\
\hline & 49.86 & $(105)$ & 1.829 & & \\
\hline \multirow{5}{*}{$60 \mathrm{~mJ}$} & 14.06 & $(002)$ & 6.299 & \multirow{5}{*}{$\begin{array}{l}1.75 \times \\
10^{-2}\end{array}$} & \multirow{5}{*}{16.8} \\
\hline & 32.35 & $(100)$ & 2.768 & & \\
\hline & 39.44 & (103) & 2.285 & & \\
\hline & 44.13 & $(006)$ & 2.052 & & \\
\hline & 49.83 & (105) & 1.820 & & \\
\hline \multirow{5}{*}{$80 \mathrm{~mJ}$} & 14.03 & $(002)$ & 6.312 & \multirow{5}{*}{$\begin{array}{l}1.96 \times \\
10^{-2}\end{array}$} & \multirow{5}{*}{16.6} \\
\hline & 32.19 & $(100)$ & 2.781 & & \\
\hline & 39.39 & $(103)$ & 2.287 & & \\
\hline & 44.11 & $(006)$ & 2.053 & & \\
\hline & 49.81 & $(105)$ & 1.831 & & \\
\hline
\end{tabular}

The number of layers could be determined using this morphological deviation [26]. A single dark line at the folded edge could be related to a monolayer [27]. The TEM results indicate that the $\mathrm{MoS}_{2}$ prepared in this study is a monolayer/few layered.

\subsection{CHEMICAL-BOND STUDY}

The crystalline structure of $\mathrm{MoS}_{2}$ was further investigated by Raman spectroscopy. Figure 5 shows the Raman spectra of the multilayer and few-layered $\mathrm{MoS}_{2}$ flakes excited by $488 \mathrm{~nm}$ in the air environment. There are two types of singlelayer $\mathrm{MoS}_{2}, 2 \mathrm{H}-\mathrm{MoS}_{2}$ and $1 \mathrm{~T}-\mathrm{MoS}_{2}$, which 1T$\mathrm{MoS}_{2}$ is metastable. $2 \mathrm{H}$ corresponds to 2 layers per $\mathrm{H}$ (hexagonal) unit cell, and $1 \mathrm{~T}$ is one layer per (trigonal) unit cell, and also a mixture of several poly types in the one sample is possible. In the bulk $\mathrm{MoS}_{2}$ sample, characteristic $\mathrm{E}_{2 \mathrm{~g}}{ }^{1}$ and $A_{1 \mathrm{~g}}$ observe at 384 and $410 \mathrm{~cm}^{-1}$, respectively. These vibrations related to the in-plane opposite of S-Mo and out-of-plane vibrations in sulphur atoms correspondingly [28].

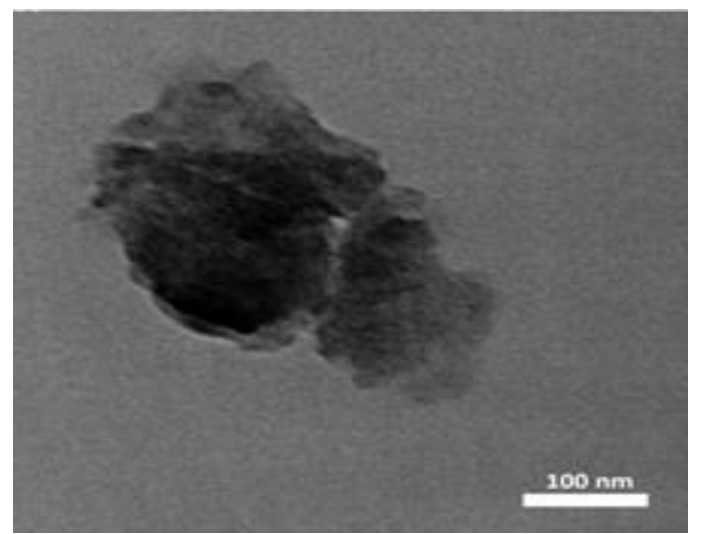

a)

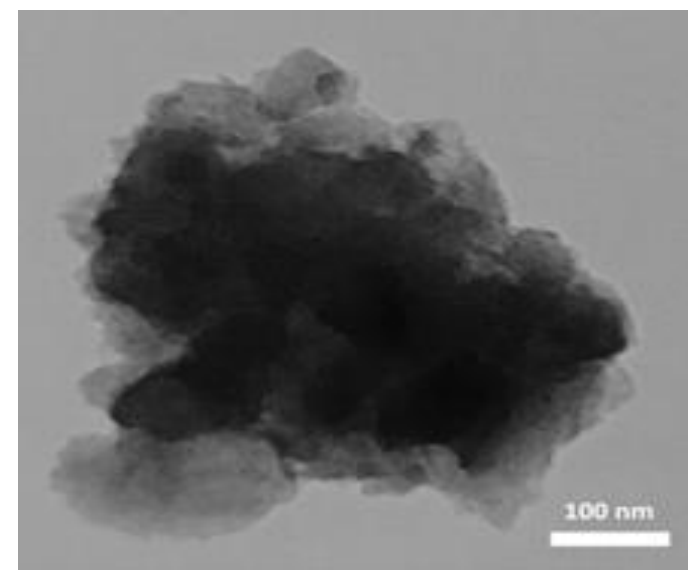

b)

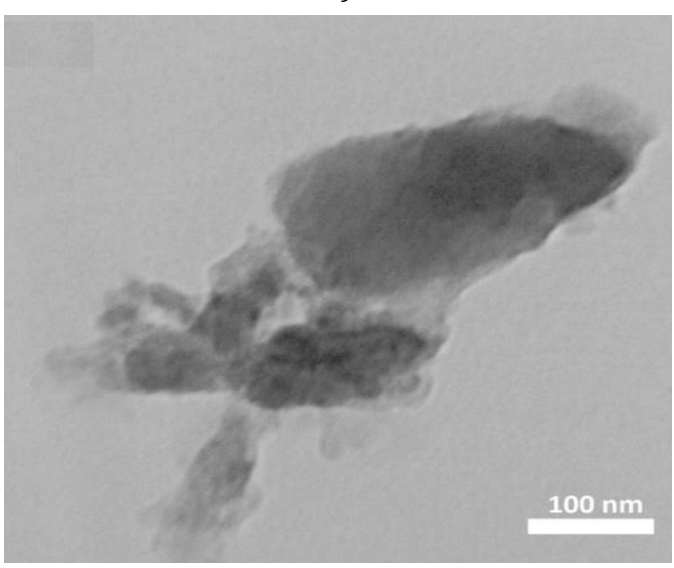

c) 


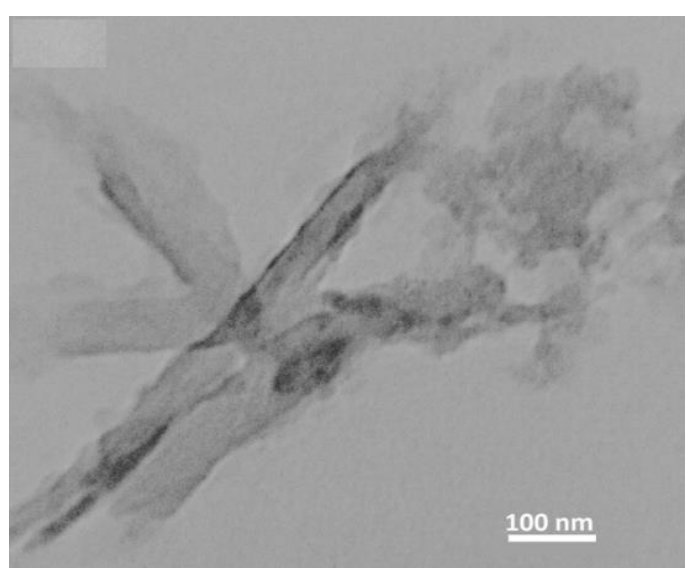

d)

Fig. 4. TEM images of a) $\mathrm{MoS}_{2}$ nanosheets, b) fewlayered $\mathrm{MoS}_{2}$ flakes after $40 \mathrm{~mJ}$, c) $60 \mathrm{~mJ}$, d) $80 \mathrm{~mJ}$ laser energy.
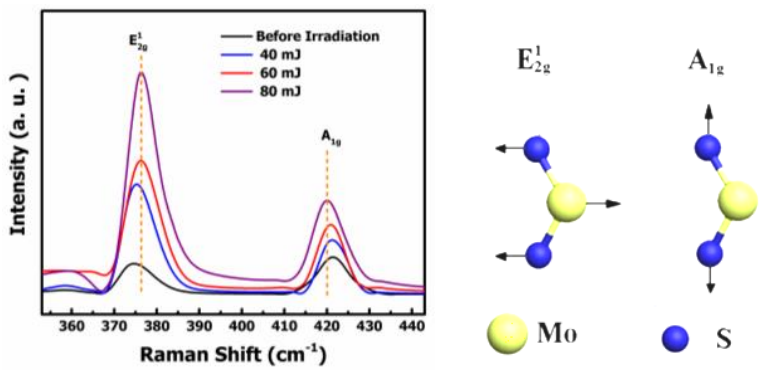

Fig. 5. Raman spectra of the $\mathrm{MoS}_{2}$ samples before and after laser irradiation under different laser energies.

By exfoliation of $\mathrm{MoS}_{2}$ to nanosheets, the electronic structure would change profoundly compared to the bulk species. Mostly, $\mathrm{MoS}_{2}$ dichalcogenides formation occurs in the $2 \mathrm{H}$ form of hexagonal. Although the $2 \mathrm{H}$ forms are semiconducting, the $1 \mathrm{~T}$ forms are metallic [29]. The up-shift of Raman peaks in $2 \mathrm{H}-\mathrm{MoS}_{2}$ measured as a function of applied hydrostatic pressure can be explained by the presence of strain [24,30]. The $\mathrm{E}_{2 \mathrm{~g}}{ }^{1}$ and $\mathrm{A}_{1 \mathrm{~g}}$ peaks position, as well as the frequency difference, could be attributed to the change of the $\mathrm{MoS}_{2}$ layer numbers [31]. The number of layers depends on the frequency difference $(\Delta \omega)$ between $E_{2 g}{ }^{1}$ and $\mathrm{A}_{1 \mathrm{~g}}$ modes of $\mathrm{MoS}_{2}$ [32]. Figure 5 exhibits two characteristic peaks, corresponding to two phonon modes of $\mathrm{MoS}_{2}, \mathrm{E}_{2 \mathrm{~g}} 1 \sim 375 \mathrm{~cm}^{-1}$ and $\mathrm{A}_{1 \mathrm{~g}} \sim 420 \mathrm{~cm}^{-1}$, the typical spectra for $\mathrm{MoS}_{2}$ [33]. The $\mathrm{E}_{2 \mathrm{~g}}{ }^{1}$ mode signifies the in-layer displacements of Mo and $S$ atoms and the $A_{1 g}$ mode represents the out-oflayer displacements of $S$ atoms along the c-axis [34]. It is found that the frequency of $E_{2 \mathrm{~g}}{ }^{1}$ peak increase while that of the $A_{1 g}$ peak decrease as a result of the reduction layer number. By increasing the layer numbers, vibrations of atoms would be suppressed by the Van der Waals force between the layers leading to the higher force constants $[31,35]$. The red-shift of $A_{1 g}$ peak and blue-shift of $\mathrm{E}_{2 \mathrm{~g}}{ }^{1}$ peak signifying negligible interlayer Van der Waals forces whereas stacking induced the structure changes in multilayer $\mathrm{MoS}_{2}$ [35]. Furthermore, the intensity of the peaks for $\mathrm{MoS}_{2}$ after laser irradiation obtained as relatively high and broader compared to the other sample. This shows the thickness reduction in the of $\mathrm{MoS}_{2}$ flakes [36]. The observed position and expansion of the peaks would be related to surface reconstruction. It is obvious that the $A_{1 g}$ mode was found to soften (decreasing of the frequency, which is accompanied by position changes of the atoms in a unit cell) probably because of the surface reconstruction [37]. This evidence confirms that the interlayer bonding and lattice dynamics would be affected by the weak interlayer interaction through surface reconstruction and vibrational softening [38]. The same perceptive may apply to few-layer $\mathrm{MoS}_{2}$ samples. This makes possible using Raman frequencies as an indicator of the layer thickness. These results confirm exfoliation of the $\mathrm{MoS}_{2}$ to few-layer form.

Table 2. Calculated $\Delta \omega$ and FWHM form Fig. 5.

\begin{tabular}{|c|c|c|c|c|}
\hline Sample & $\begin{array}{c}\text { Before } \\
\text { irradiation }\end{array}$ & $40 \mathrm{~mJ}$ & $60 \mathrm{~mJ}$ & $80 \mathrm{~mJ}$ \\
\hline$\Delta \omega\left(\mathrm{cm}^{-1}\right)$ & 48 & 46 & 45 & 43 \\
\hline FWHM $\left(\mathrm{E}_{2 \mathrm{~g}}^{1}\right)$ & 9 & 11 & 12 & 14 \\
\hline FWHM $\left(\mathrm{A}_{1 \mathrm{~g}}\right)$ & 6 & 7 & 9 & 10 \\
\hline
\end{tabular}

The prediction of layer number by Raman frequency difference is not a precise estimation for grown $\mathrm{MoS}_{2}$, it correspondingly was confirmed by TEM. However, the typical $\Delta \omega$ of the synthesized nanosheets is larger than the reported value of exfoliated $\mathrm{MoS}_{2}$ [32]. Further study is needed to understand this phenomenon. The calculated data for $\Delta \omega$ and Full width at half maximum (FWHM) of the samples are collected in Table 2.

\subsection{TRIBOLOGICAL CONSIDERATIONS}

Zeta potential is associated with the charge on the particle's surface that influences on the properties of the colloidal materials such as their stability. The Zeta potential values can be used to define the double-layer properties of a colloidal dispersion. The higher Zeta- potential demonstrates that the colloid is more stable. When Zeta potential is less negative than $-15 \mathrm{mV}$, it is the beginning of particles agglomeration. The properties of the 
particle-liquid interface which studied by Zeta potential analysis could lead to practical applications by understanding the physical properties of suspensions and colloids. Nanoparticles with Zeta Potential values greater than $30 \mathrm{mV}$ have high degrees of stability [39]. Particles aggregation would occur due to the Van der Waal interactions between particles with a low Zeta potential value. The agglomeration and stability of the samples based on the Zeta potential absolute values, which determines the static repellency of nanomaterials dispersed in oil, are shown in Fig. 6.

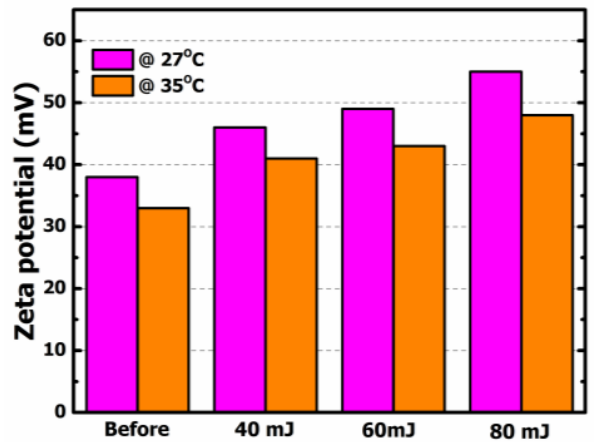

Fig. 6. Zeta potential of the $\mathrm{MoS}_{2}$ samples with various laser irradiation at $27^{\circ} \mathrm{C}$ and $35^{\circ} \mathrm{C}$.

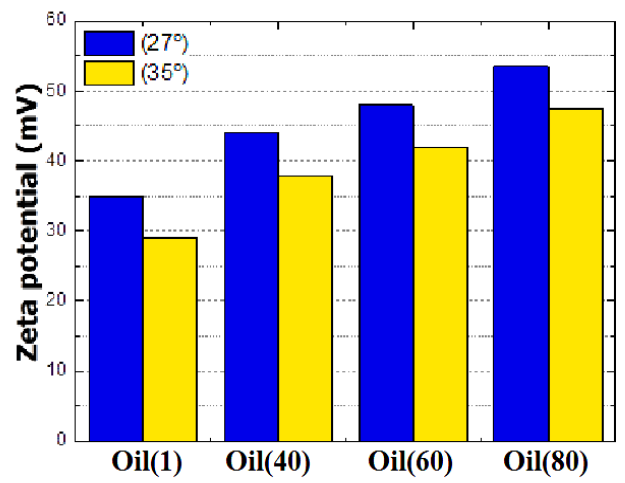

a)

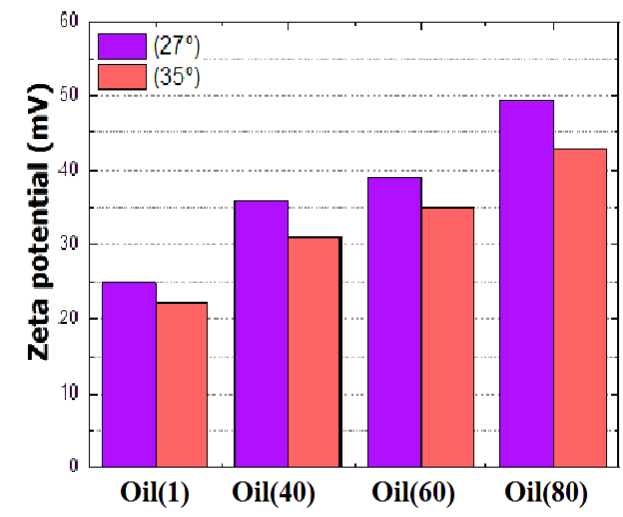

b)

Fig. 7. Zeta potential of the MoS_2 samples with various laser irradiation at $27{ }^{\circ} \mathrm{C}$ and $35{ }^{\circ} \mathrm{C}$ after a) one week and b) 18 months.
The maximum value of Zeta potential for $\mathrm{MoS}_{2}$ nanosheets and few-layered $\mathrm{MoS}_{2}$ flakes in oil was obtained for $80 \mathrm{~mJ}$ of laser energy, which was ascribed to the optimum concentration of the few-layered $\mathrm{MoS}_{2}$ flakes in the base oil. This high value of Zeta potential specifies enhanced nanomaterials dispersion in the base oil. For the samples under various laser energies, the absolute values of Zeta potential at $27^{\circ} \mathrm{C}$ and 35 ${ }^{\circ} \mathrm{C}$, are in the range of $32-54 \mathrm{mV}$, which is excellent stability.

To study the long-term stability of the additive in oil dispersions, Zeta Potential was done after one week and 18 months. It is obvious that after one week there is no change in Zeta Potential and after 18 months slight variations can be seen in Zeta Potential (Fig. 7).

Hydraulic oil is used to transmit pressure and energy and exhibit a constant viscosity regardless of its temperature. Many variables such as oil quality, operative parameters, and possible contamination would affect the lifespan of the hydraulic oil. Low-quality hydraulic oil will stimulate additional wear in the hydraulics and transmission. Hydraulic fluid can act as a sealant, coolant, and lubricant in equipment. In all hydraulic and lubricating fluids, practical limits were determined on the adequate operating temperature range, including high and low levels. Hydraulic fluids with high temperatures mostly damage materials used as seal compounds and accelerate the degradation of the oil. Besides, the viscosity of the fluid falls below the optimum value for the hydraulic system's components in hightemperature ranges. Composition of the fluid and the operative temperature are two main parameters defining the viscosity of hydraulic fluid. Low viscosity boundary is determined by the lubrication features of the oil and its resistance to cavitation, while the upper viscosity value is limited by the ability of the oil to be pumped. The viscosity also determines the safety operative windows for the hydraulic system by controlling the oil temperature. Hydraulic oil viscosity is remarkable at low temperatures because when the temperature is too low fluid viscosity is high.

Optimal properties of hydraulic oils studied by a combination of base oil and additives. They possess most of the essential characteristics of hydraulic oils. Additives in the base oils enhance 
the anti-friction features as well as chemical and physical properties.

As mentioned earlier, viscosity is one of the most critical criteria in the selection of hydraulic fluid. There is a misunderstanding about the viscosity of the hydraulic fluid which reducing its viscosity will decrease operating temperatures, while higher viscosities may lead to a reduction in operating temperatures in applications. This phenomenon comes from the fact that hydraulic fluid with low viscosity reduces the volumetric efficiency of pumps and cause fluid overheating.

Table 3 presents the results of Oil Analysis Condition Monitoring of the samples and pure oil. The kinematic viscosity of the base oil and the samples under various laser energies were calculated at 40 and $100{ }^{\circ} \mathrm{C}$, which decreases with increasing the temperature. The maximum acceptable kinematic viscosity is $300 \mathrm{cSt}$ (DIN.51.381). Low (high) viscosity causes lubricant (hydraulic) ability of the oil. Therefore, at $40^{\circ} \mathrm{C}$ the samples show hydraulic properties.

Table 3. Oil Analysis Condition Monitoring of the samples and pure oil.

\begin{tabular}{|c|c|c|c|c|c|c|c|}
\hline Test & Unit & T.T. $\left.^{\circ}{ }^{\circ} \mathrm{C}\right)$ & Oil (0) & Oil (1) & Oil (40) & Oil (60) & Oil (80) \\
\hline $\begin{array}{c}\text { Kinematic } \\
\text { Viscosity }\end{array}$ & $\mathrm{cSt}$ & 40 & 61.01 & 65.23 & 68.69 & 73.26 & 72.33 \\
\hline $\begin{array}{c}\text { Kinematic } \\
\text { Viscosity }\end{array}$ & $\mathrm{cSt}$ & 100 & 10.25 & 12.34 & 14.23 & 15.22 & 16.24 \\
\hline $\begin{array}{c}\text { Viscosity } \\
\text { Index }\end{array}$ & - & - & 156 & 159 & 159 & 160 & 163 \\
\hline Density & $\mathrm{Kg} / \mathrm{m}^{3}$ & 15 & 850 & 865 & 853 & 857 & 856 \\
\hline Pour Point & ${ }^{\circ} \mathrm{C}$ & - & -35 & -30 & -33 & -37 & -39 \\
\hline Flash Point & ${ }^{\circ} \mathrm{C}$ & - & 250 & 255 & 262 & 266 & 285 \\
\hline
\end{tabular}

*Test Temperature

The viscosity index is proportional to the inverse of temperature variations. It means when the viscosity index is high, the changes of viscosity with the variations of the temperature is low. By controlling the viscosity at optimized levels is possible to stabilize the oil film even at high temperatures. The viscosity higher than 130 is the standard application (DIN.51.381). The density of the oil increases by additives, but after laser irradiation, a reduction in density occurs. It means that multilayer $\mathrm{MoS}_{2}$ has changed to fewlayered $\mathrm{MoS}_{2}$ flakes confirming TEM results.

Based on Table 3, the range of pour point and flash point after laser irradiation has been increased compared to the base oil. Therefore, the oil has a more extensive application range.

By reducing the friction coefficient due to friction modifiers, less fuel will be consumed. Most of these modifiers have the layered molecular structure, which makes the particles easily slide over each other. Figure 8 shows the friction coefficient as a function of time for the submitted to different laser intensity. According to Fig. 8, the friction coefficient of the Oil (80) is always lower than that of the other samples.

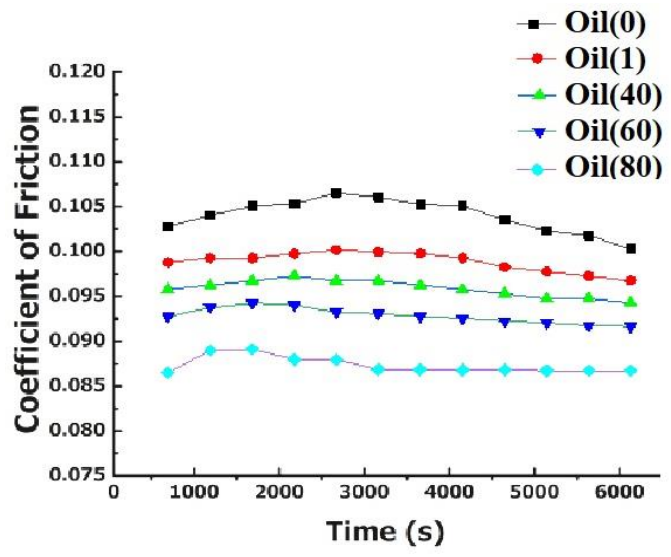

Fig. 8. Friction coefficient versus time by the four-ball test for the samples summitted to different laser intensities.

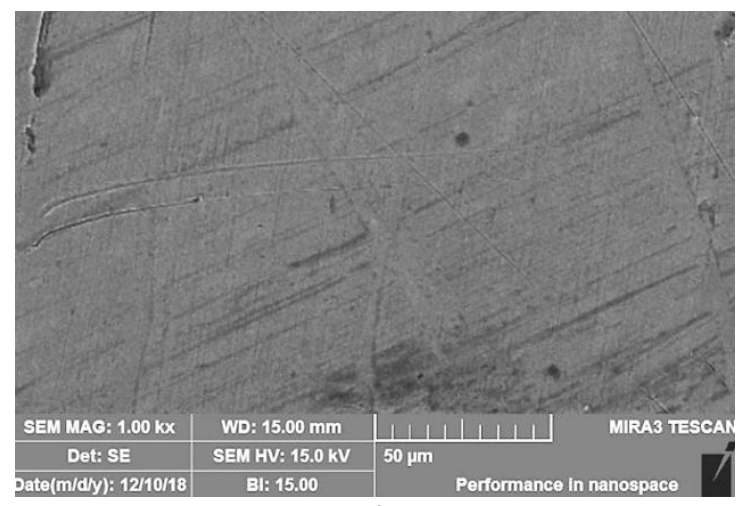

a)

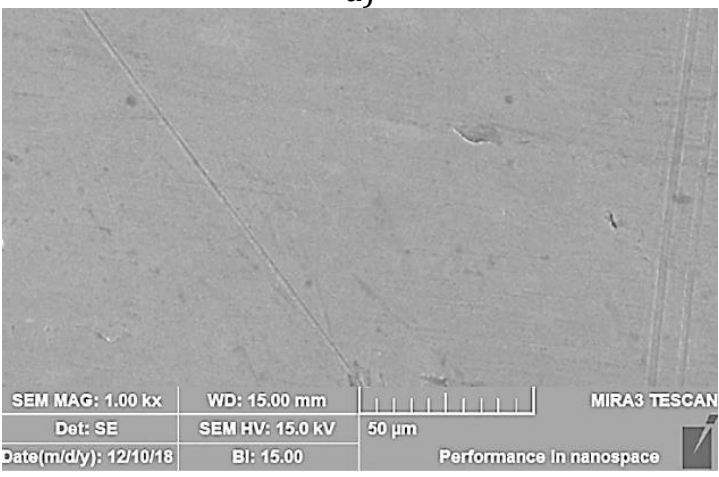

b)

Fig. 9. Wear scar of the upper ball on the contacted surface with lubrication using the a) Oil (0), b) and Oil (80). 
Figure 9 shows the SEM images of the produced worn surfaces using Oil (0) and Oil (80). The rubbed surface of the Oil (0) shows wide and deep ruts compared to the Oil (80). As expected, strong adherence of a film formed by the nanosheets to the contacts on the rubbing surfaces could enhance the tribological properties. However, the superior friction reduction and anti-wear behaviour of dispersed few-layered $\mathrm{MoS}_{2}$ in oil are distinct for metal-tometal contact at interfaces.

To be expected, these results indicate that the few-layered MoS2 are suitable materials and could help the lubricant via friction reduction.

The wear scar diameter (WSD) can be calculated with the details in ref [40]. The plots of WSD for the samples after one week and 18 months are shown in Fig. 10. It can be seen that the WSDs in the presence of the additive is reduced. The most reduction are $26.8 \%$ (after one week) and $25 \%$ (after 18 months) for Oil (80) compared with base Oil (0).

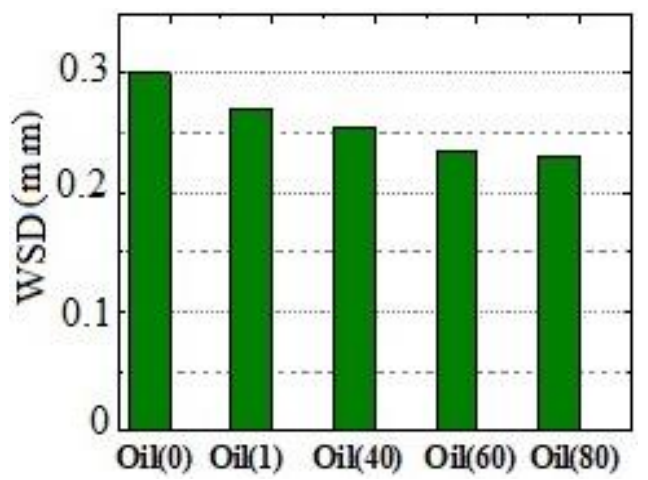

a)

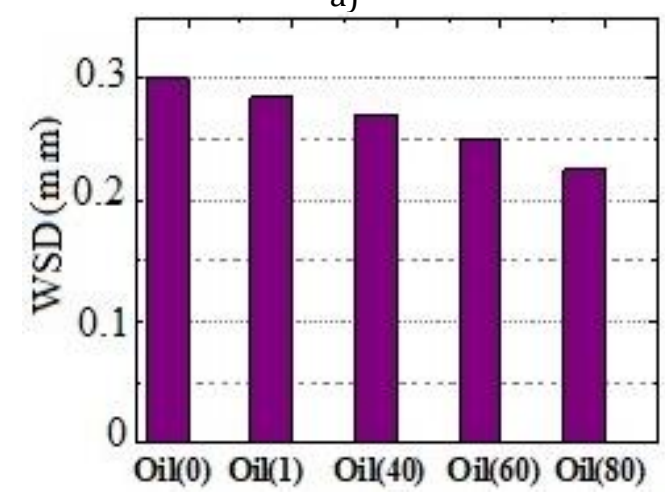

b)

Fig. 10. Wear scar diameter of the samples after a) one week and b) 18 months.

Flash Temperature Parameter (FTP) was first introduced by Lane [41]. FTP is the limit of temperature that oil makes the lubricating films properly lubricate. The higher FTP points out the better lubrication performance. When FTP is low, the lubrication films are broken down and as a result lubrication performance is poor.

$$
\mathrm{FTP}=\frac{\text { Applied load }}{(\text { Wear scan diameter })^{1 / 4}}=\frac{W}{d^{1.4}}
$$

where $\mathrm{W}$ indicates the applied load in $\mathrm{kg}$, and $\mathrm{d}$ is the value of the wear scar diameter (WSD) in $\mathrm{mm}$.

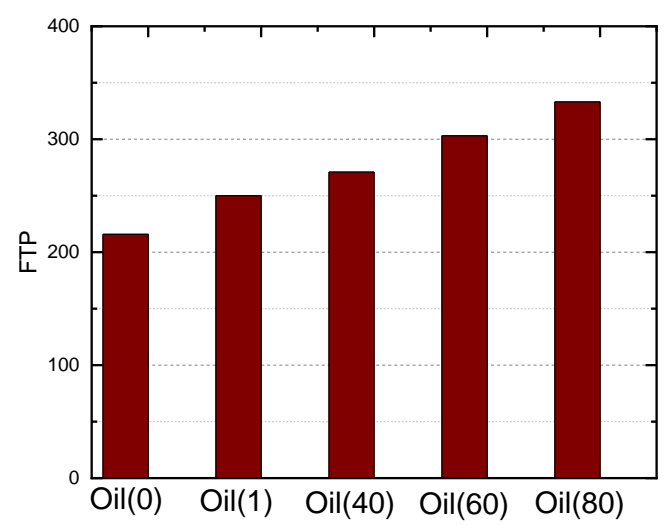

a)

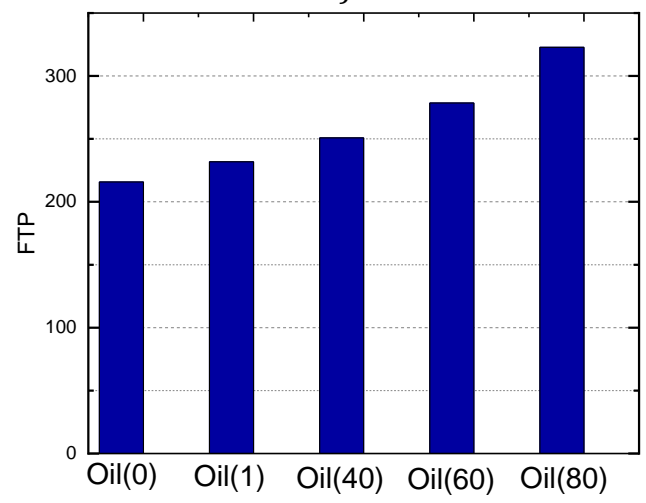

b)

Fig. 11. FTP of the samples after a) one week and b) 18 months.

The results of FTP calculation are shown in Fig. 11 , with an applied load of $40 \mathrm{~kg}$. FTP of Oil (80) has increased $54.3 \%$ (after one week) and 49.6 $\%$ (after 18 months) compared with base Oil (0).

\section{CONCLUSION}

We reported a novel method to synthesize the fewlayered $\mathrm{MoS}_{2}$ flakes using the hydrothermal method and the laser irradiation assistant method. The presented process enables large-scale production of few-layered $\mathrm{MoS}_{2}$ flakes from $\mathrm{MoS}_{2}$ nanosheets. XRD patterns confirmed the reduction of crystallite size. TEM images showed exfoliation of $\mathrm{MoS}_{2}$ nanosheets. The tribology investigations of 
few-layered $\mathrm{MoS}_{2}$ flakes exhibited decreasing of the friction coefficient under laser irradiation. The stability of few-layered $\mathrm{MoS}_{2}$ flakes dispersed in oil corroborated by Zeta potential measurements of the samples. The results of the kinematic viscosity evaluation showed its increasing under laser energy, which is excellent for hydraulic oil. In addition, lubricant film building capability was analyzed by increasing temperature. The range of pour point and flash point after laser irradiation increased. The wear scar diameter reduction and enhancement of FTP of Oil (80) were $26.8 \%$ and $54.3 \%$ compared with base Oil (0) after one week, respectively. The results showed that adding laserirradiated samples to the pure oil, as well as increasing the laser energies from 40 to $80 \mathrm{~mJ}$, makes few-layered $\mathrm{MoS}_{2}$ flakes a favorable behavior for hydraulic utilization.

\section{REFERENCES}

[1] A. Splendiani, L. Sun, Y. Zhang, T. Li, J. Kim, C.Y. Chim, G. Galli, and F. Wang, Emerging photoluminescence in monolayer MoS2, Nano letters, vol. 10, no. 4. pp. 1271-1275, 2010, doi: $10.1021 / \mathrm{nl} 903868 \mathrm{w}$

[2] H. Shi, R. Yan, S. Bertolazzi, J. Brivio, B. Gao, A. Kis, D. Jena, HG. Xing, L. Huang, Exciton dynamics in suspended monolayer and few-layer MoS2 2D crystals, American Chemical Society, vol. 7, no. 2, pp. $1072-1080,2013$, doi: $10.1021 / n n 303973 r$

[3] Y. Li, H. Wang, L. Xie, Y. Liang, G. Hong, H. Dai, MoS2 nanoparticles grown on graphene: An advanced catalyst for the hydrogen evolution reaction, Journal of the American Chemical Society, vol. 133, pp. 7296-7299, 2011, doi: 10.1021/ja201269b

[4] J.D. Benck, T.R. Hellstern, J. Kibsgaard, P. Chakthranont, T.F. Jaramillo, Catalyzing the Hydrogen Evolution Reaction (HER) with Molybdenum Sulfide Nanomaterials, American Chemical Society Catalysis, vol. 4, pp. 39573971, 2014, doi: 10.1021/cs500923c

[5] B. Radisavljevic, A. Radenovic, J. Brivio, V. Giacometti, A. Kis, Single-layer MoS2 transistors, Nature Nanotechnology, vol. 6, pp. 147-150, 2011, doi: 10.1038/nnano.2010.279

[6] P. Gao, Z. Yang, G. Liu, Q. Qiao, Facile synthesis of MoS2/MWNT anode material for high performance lithium-ion batteries, Ceramics International, vol. 41, iss. 1, pp. 1921-1925, 2015, doi: 10.1016/j.ceramint.2014.09.132
[7] X. Wang, B. Li, D.R. Bell, W. Li, R. Zhou, Hydrogen and methane storage and release by MoS2 nanotubes for energy storage, Journal of Materials Chemistry A, vol. 5, pp. 23020-23027, 2017, doi: 10.1039/C7TA05995G

[8] M. Shanmugan, T. Bansal, C.A. Durcan, B. Yu, Molybdenum disulphide/titanium dioxide nanocomposite poly 3-hexylthiophene bulk heterojunction solar cell, Applied Physics Letters, vol. 100, iss. 15, pp. 153901-153905, 2012, doi: 10.1063/1.3703602

[9] F. Lavini, A. Calò, Y. Gao, E. Albisetti, T. Cao, G. Li, L. Cao, C. Aruta, E. Riedo, Friction and work function oscillatory behavior for an even and odd number of layers in polycrystalline MoS2, Nanoscale, vol. 10, pp. 8304-8312, 2018, doi: 10.1039/C8NR00238J

[10] Z.J. Ye, A. Balkanci, A. Martini, M.Z. Baykara, Effect of roughness on the layer-dependent friction of few-layer graphene, Physical Review B, vol. 96, pp. 115401, 2017, doi: 10.1103/PhysRevB.96.115401

[11] S. Dominguez-Meister, T.C. Rojas, M. Brizuela, J.C. Sanchez-Lopez, Solid lubricant behaviour of MoS2 and WSe2-based nanocomposite coatings, Science and Technology of Advanced Materials, vol. 18, iss. 1, pp. 122-133, 2017, doi: 10.1080/14686996.2016.1275784

[12] G.T. Semione, G.D.L. Semione, C. Bernardi, R. Binder, J.D.B. de Mello, V. Drago, Synthesis of nanostructured flower-like MoS2 and its friction properties as additive in lubricating oils, Industrial Lubrication and Tribology, vol. 68, no. 6, pp. 658-664, 2016, doi: 10.1108/ILT-122015-0194

[13] M.R. Vazirisereshk, A. Martini, D.A. Strubbe, M. Z. Baykara, Solid Lubrication with MoS2: A Review, Lubricants, vol. 7, no. 7, p. 57, 2019, doi: 10.3390/lubricants7070057

[14] H.S. Khare, D.L. Burri, The Effects of Environmental Water and Oxygen on the Temperature-Dependent Friction of Sputtered Molybdenum Disulfide, Tribology Letters, vol. 52, pp. 485-493, 2013, doi: 10.1007/s11249-013-0233-8

[15] M.S. Charoo, M.F. Wani, M. Hanief, M.A. Rather, Tribological Properties of MoS2 Particles as Lubricant Additive on EN31 Alloy Steel and AISI 52100 Steel Ball, Materials Today: Proceedings, vol. 4, iss. 9, pp. 9967-9971, 2017, doi: 10.1016/j.matpr.2017.06.303

[16] H. Xie, B. Jiang, J. He, X. Xia, F. Pan, Lubrication performance of MoS2 and SiO2 nanoparticles as lubricant additives in magnesium alloy-steel contacts, Tribology International, vol. 93, pp. 6370, 2016, doi: 10.1016/j.triboint.2015.08.009 
[17] C. Altavilla, M. Sarno, P. Ciambelli, A. Senatore, V. Petrone, New 'chimie douce' approach to the synthesis of hybrid nanosheets of MoS2 on CNT and their anti-friction and anti-wear properties, Nanotechnology, vol. 24, no. 12, pp. 125601125612, 2013, doi: 10.1088/0957$4484 / 24 / 12 / 125601$

[18] Q. Liu, X. Li, Q. He, A. Khalil, D. Liu, T. Xiang, X. $\mathrm{Wu}$, L. Song, Gram-Scale Aqueous Synthesis of Stable Few-Layered 1T-MoS2: Applications for Visible-Light-Driven Photocatalytic Hydrogen Evolution, Small, vol. 11, iss. 41, pp. 5556-5564, 2015, doi: 10.1002/smll.201501822

[19] J. Sun, X. Li, W. Guo, M. Zhao, X. Fan, Y. Dong, C. $\mathrm{Xu}$, J. Deng, Y. Fu, Synthesis Methods of TwoDimensional MoS2: A Brief Review, Crystals, vol. 7, iss. 7, pp. 198-209, 2017, doi: $10.3390 /$ cryst7070198

[20] P. Afanasiev, Synthetic approaches to the molybdenum sulphide materials, Comptes Rendus Chimie, vol. 11, iss. 1-2, pp. 159-182, 2008, doi: 10.1016/j.crci.2007.04.009

[21] B. Bindhu, B.K. Sharu, M.S. Gopika, P.K. Praseetha, K. Veluraja, Molybdenum disulfide nano flakes through Li-AHA assisted exfoliation in an aqueous medium, Royal Society of Chemistry Advances, vol. 6, iss. 26, pp. 22026-22033, 2016, doi: 10.1039/C5RA25368C

[22] V.H. Pham, K.H. Kim, D.W. Jung, K. Singh, E.S. Oh, J.S. Chung, Liquid phase co-exfoliated MoS2graphene composites as anode materials for lithium ion batteries, Journal of Power Sources, vol. 244, pp. 280-286, 2013, doi: 10.1016/j.jpowsour.2013.01.053

[23] G.K. Williamson, W.H. Hall, X-ray line broadening from filed aluminium and wolfram, Acta metallurgica, vol. 1 , iss. 1 , pp. $22-31,1953$, doi: 10.1016/0001-6160(53)90006-6

[24] M. Viršek, A. Jesih, I. Milošević, M. Damnjanović, M. Remškar, Raman scattering of the MoS2 and WS2 single nanotubes, Surface science, vol. 601, iss. 13, pp. 2868-2872, 2007, doi: $10.1016 / j . s u s c .2006 .12 .050$

[25] P. Lu, X. Wu, W. Guo, X.C. Zeng, Straindependent electronic and magnetic properties of MoS 2 monolayer, bilayer, nanoribbons and nanotubes, Physical Chemistry Chemical Physics, vol. 14, no. 37, pp. 13035-13040, 2012, doi: 10.1039/C2CP42181J

[26] J.C. Meyer, A.K. Geim, M.I. Katsnelson, K.S. Novoselov, T.J. Booth, S. Roth, The structure of suspended graphene sheets, Nature, vol. 446, pp. 60-63, 2007, doi: 10.1038/nature05545
[27] S. Patil, A. Harle, S. Sathaye, K. Patil, Development of a novel method to grow mono/few-layered MoS 2 films and MoS 2-graphene hybrid films for super capacitor applications, Crystal Engineering Communication, vol. 16, iss. 47, pp. 10845-10855, 2014, doi: 10.1039/C4CE01595A

[28] N. Liu, P. Kim, J.H. Kim, J.H. Ye, S. Kim, C.J. Lee, Large-area atomically thin MoS2 nanosheets prepared using electrochemical exfoliation, American Chemical Society nano, vol. 8, no. 7, pp. $6902-6910,2014$, doi: 10.1021/nn5016242

[29] A.N. Enyashin, L. Yadgarov, L. Houben, I. Popov, M. Weidenbach, R. Tenne, M. Bar-Sadan, G. Seifert, New Route for Stabilization of 1T-WS2 and MoS2 Phases, The Journal of Physical Chemistry C, vol. 115 , no. 50, pp. 24586-24591, 2011, doi: 10.1021/jp2076325

[30] A.G. Bagnall, W.Y. Liang, E.A. Marseglia, B. Welber, Raman studies of MoS2 at high pressure, Physica B+C, vol. 99, iss. 1-4, pp. 343-346, 1980, doi: 10.1016/0378-4363(80)90257-0

[31] H. Li, Q. Zhang, C.C. Yap, B.K. Tay, T.H. Edwin, A. Olivier, D. Baillargeat, From Bulk to Monolayer MoS2: Evolution of Raman Scattering, Advanced Functional Materials, vol. 22, iss. 7, pp. 13851390, 2012, doi: 10.1002/adfm.201102111

[32] Y. Yu, C. Li, Y. Liu, L. Su, Y. Zhang, L. Cao, Controlled Scalable Synthesis of Uniform, HighQuality Monolayer and Few-layer MoS2 Films, Scientific Reports, vol. 3, pp. 1866-1872, 2013, doi: 10.1038/srep01866

[33] U. Gupta, B.S. Naidu, U. Maitra, A. Singh, S.N. Shirodkar, U.V. Waghmare, C.N. Rao, Characterization of few-layer 1 T-MoSe2 and its superior performance in the visible-light induced hydrogen evolution reaction, Applied Materials vol. 2, iss. 9, pp. 092802-092809, 2014, doi: $10.1063 / 1.4892976$

[34] T. Korn, S. Heydrich, M. Hirmer, J. Schmutzler, C. Schüller, Low-temperature photo carrier dynamics in monolayer MoS2, Applied Physics Letters, vol. 99, iss. 10, pp. 102109-102113, 2011, doi: $10.1063 / 1.3636402$

[35] C. Lee, H. Yan, L.E. Brus, T.F. Heinz, J. Hone, S. Ryu, Anomalous lattice vibrations of single-and few-layer MoS2, American Chemical Society nano, vol. 4, no. 5, pp. 2695-2700, 2010, doi: $10.1021 / \mathrm{nn} 1003937$

[36] S.M. Notley, High yield production of photoluminescent tungsten disulphide nanoparticles, Journal of Colloid and Interface Science, vol. 396, pp. 160-164, 2013, doi: 10.1016/j.jcis.2013.01.035 
[37] P.A. Bertrand, Surface-phonon dispersion of $M o S$ 2, Physical Review B, vol. 44, iss. 11-15, pp. 5745-5749, 1991, doi: $10.1103 /$ physrevb.44.5745

[38] K.F. Mak, K. He, C. Lee, G.H. Lee, J. Hone, T.F. Heinz, J. Shan, Tightly bound trions in monolayer MoS2, Nature Materials, vol. 12, pp. 207-217, 2012, doi: 10.1038/nmat3505

[39] J.H. Lee, K.S. Hwang, S.P. Jang, B.H. Lee, J.H. Kim, S.U. Choi, C.J. Choi, Effective viscosities and thermal conductivities of aqueous nano fluids containing low volume concentrations of Al203 nanoparticles,
International Journal of Heat and Mass Transfer, vol. 51, iss. 11-12, pp. 2651-2656, 2008, doi: 10.1016/j.ijheatmasstransfer.2007.10.026

[40] A. Bos, Wear in the four-ball apparatus: relationship between the displacement of the upper ball and the diameter of the wear scars on the lower balls, Wear, vol. 41, iss. 1, pp. 191 - 194, 1977, doi: 10.1016/0043-1648(77)90201-0

[41] T.B. Lane, The flash temperature parameter: $A$ criterion for assessing EP performance in the four-ball machine, Journal of the Institute of Petroleum, vol. 43, pp. 181-188, 1957. 